\title{
Maneiras de Conhecer e Implicações para a Equidade de Gênero na Educação em Ciências
}

\section{Ways of Knowing and Implications for Gender Equity in Science Education}

\author{
Laís Gedoz ${ }^{\circledR}$ Brasil \\ Alexsandro Pereira de Pereira ${ }^{(1)}$ Brasil \\ Daniela Borges Pavani ${ }^{~}$ Brasil
}

Nos últimos anos, o debate sobre questões de gênero tem se tornado foco de interesse da pesquisa em educação em ciências no Brasil. No entanto, existe uma escassez de artigos na literatura nacional que apresentem uma base teórica para os estudos de gênero na educação em ciências. Assim, apresentamos neste trabalho as maneiras de conhecer das mulheres, segundo a abordagem de Mary F. Belenky e suas colaboradoras, como possível referencial teórico para os estudos nessa área. São delineadas cinco perspectivas através das quais as mulheres tiram conclusões sobre verdade, conhecimento e realidade: o Silêncio; o Conhecimento recebido; o Conhecimento subjetivo; o Conhecimento processual; e o Conhecimento construído. Após descrever as cinco posições epistemológicas, mostramos como o estudo dessas autoras tem sido utilizado na pesquisa em educação em ciências e como suas ideias podem contribuir para o planejamento de intervenções em sala de aula que busquem promover um ensino de ciências que seja mais equitativo com relação ao gênero.

Palavras-chave: gênero; maneira de conhecer das mulheres; ensino de ciências.

In recent years, the debate on gender issues has become a focus of interest in science education research in Brazil. Nevertheless, there is a shortage of articles in the national literature that present a theoretical basis for gender studies in science education. Thus, this paper presents the women's ways of knowing, according to the approach of Mary F. Belenky and her collaborators, as a possible theoretical framework for gender studies in this area. Five perspectives through which women draw conclusions about truth, knowledge and reality are outlined: Silence; Received knowledge; Subjective knowledge; Procedural knowledge; and the Constructed knowledge. After describing the five epistemological positions, we show how the study of these authors has been used in science education research and how their ideas can contribute to the planning of classroom interventions that seek to promote science teaching that is more equitable in relation to gender.

Keywords: gender; women's ways of knowing; science education. 


\section{Introdução}

Ao considerarmos o cenário político atual brasileiro, podemos dizer que os estudos de gênero na educação e na educação em ciências se tornam cada vez mais urgentes. A onda de ódio que assola o nosso país é uma marca do atual governo que, em defesa de uma ideologia antidemocrática, impõe uma ditadura disfarçada de democracia ${ }^{1}$. Já no seu discurso de posse em janeiro de 2019, o presidente da república prometeu combater a "ideologia de gênero" em prol dos valores das famílias brasileiras². Tais iniciativas são gravíssimas, especialmente em um país que, em 2017, passou a assumir o $5^{\circ}$ lugar em mortes violentas de mulheres no mundo, de acordo com o Alto Comissariado das Nações Unidas para os Direitos Humanos (ACNUDH), e de lá para cá vê esta taxa crescer ${ }^{3}$. O governo federal adota um discurso machista, racista e homofóbico, que encontra eco em parcelas da sociedade. Tal postura busca questionar conquistas em Direitos Humanos, aí incluídos avanços em questões relativas a direitos sexuais e reprodutivos, igualdade de gênero e à condição da comunidade LGBT, mas também avança contra conquistas trabalhistas e civilizatórias.

O cenário atual, que dá protagonismo a posturas representadas pelas falas do presidente da república e muitos de seus ministros, inclusive o da educação, vem sendo construído em cima de retrocessos que são anteriores ao atual governo e se manifestam na descontinuidade e desconstrução de políticas, programas e ações voltadas à equidade de gênero ${ }^{4}$ e de enfrentamento da violência contra a mulher. Tais programas e ações foram sendo estruturados e implementados a partir da influência da Constituição de 1988 (Constituição da República Federativa do Brasil, 1988). Em 2006 entra em vigor a Lei 11.340 - Maria da Penha (Lei n. 11.340, 2006) que cria mecanismos que visam coibir a violência doméstica e familiar, estabelecendo medidas de assistência, atendimento e proteção e realizando um movimento necessário no sentido de situar a violência de gênero como resultado das desigualdades socialmente construídas. No que diz respeito à educação, novas leis, diretrizes, pareceres e normas técnicas foram sendo estabelecidas na sequência. Em 2007 foi publicado o Plano Nacional de Educação em Direitos Humanos (Comitê Nacional de Educação em Direitos Humanos, 2007); em 2012 o Parecer CNE/CP n. ${ }^{\circ}$ 8/2012 que instituiu as Diretrizes Nacionais para a Educação em Direitos Humanos, documento que promove a discussão da Educação em Direitos Humanos em ambiente educacional escolar (MEC, 2012a). Antes disso, temos a

$1 \mathrm{http}: / /$ www.boaventuradesousasantos.pt/media/As\%20democracias\%20tamb\%C3\%A9m\%20morrem\%20 democraticamente_24Out2018.pdf, acesso em 28 de fevereiro de 2020.

2_http://g1.globo.com/globo-news/jornal-globo-news/videos/t/videos/v/discurso-de-posse-do-presidente-jairbolsonaro-no-congresso-nacional/7269434/, acesso em 28 de fevereiro de 2020.

3 https://exame.abril.com.br/brasil/taxa-de-feminicidios-no-brasil-e-a-quinta-maior-do-mundo/ acesso em 28 de fevereiro de 2020.

4 Aqui consideramos equidade de gênero como definido no ABC of Women Worker's Rights and Gender Equality: "Equidade de gênero significa justiça no tratamento de homens e mulheres de acordo com suas respectivas necessidades. Isso pode incluir tratamento igual ou diferente, mas que é considerado equivalente em termos de direitos, benefícios, obrigações e oportunidades. (ILO, 2000, pág. 92, tradução nossa). 
Resolução CNE/CEB 3/2010 que institui as Diretrizes Operacionais para a Educação de Jovens e Adultos; o Parecer 17/2001 que institui as Diretrizes Nacionais para a Educação Especial na Educação Básica; Parecer 003/2004 que Institui Diretrizes Curriculares Nacionais para a Educação das Relações Étnico-Raciais e para o Ensino de História e Cultura Afro-Brasileira e Africana. Posteriormente temos a Resolução CNE/CEB no 5, de 2012 que Define Diretrizes Curriculares Nacionais para a Educação Escolar Indígena na Educação Básica MEC (2012c); a Resolução nº 8, de 2012 que Define a Educação Escolar Quilombola MEC (2012d); a Resolução no 2 de 2012 que Define a Educação Ambiental MEC (2012b).

Estes regramentos incidiram sobre o Plano Nacional de Educação/PNE 20142024 (Lei n. 13.005, 2014) assim como as disputas em torno de pautas centrais, tais como a implementação de uma educação não sexista. O PNE estabelece diretrizes, metas e estratégias para a educação no país, voltadas à universalização e à melhoria da educação básica e superior. A tramitação do documento no Congresso, em 2014, foi marcada por disputas levantadas pelas bancadas políticas religiosas e conservadoras, que resultaram na retirada do termo "gênero" do Plano. Assim, na versão aprovada do texto restou o objetivo genérico de erradicação de toda forma de discriminação. Apesar deste retrocesso, considerando todo o debate nacional já acumulado, o documento final inclui metas fundamentais ao avanço da educação no Brasil, e também aponta de forma geral a importância do enfrentamento de desigualdades e da valorização da diversidade. Portanto, é fundamental pensarmos e construirmos caminhos para uma educação em ciências que incorpore os estudos de gênero e contribua para o estabelecimento da escola como um espaço de discussão e debates sobre relações de gênero e equidade de gênero, tanto da prática docente quanto nas relações sociais e afetivas que nela se estabelecem. O investimento na educação que contextualiza e valoriza o papel das mulheres necessita ser permanente.

No Brasil, os estudos de gênero na educação em ciências ainda são relativamente escassos. De acordo com a recente revisão da literatura apresentada por Heerdt et al. (2018), entre os anos de 2008 e 2018 foram publicados apenas 34 artigos que abordam questões de gênero nas áreas de Ensino e de Educação. Nessa revisão, as autoras examinaram todas as revistas nacionais (90 no total) dos estratos A1, A2 e B1 do Qualis Periódicos, avaliadas no quadriênio 2013-2016. Este cenário, no entanto, parece estar mudando. A própria revisão de Heerdt et al. (2018) aponta um aumento relativo no número de artigos sobre questões de gênero publicados no período de 2014-2017. O mesmo aumento é observado no número de trabalhos apresentados em eventos como o da Associação Nacional de Pós-Graduação e Pesquisa em Educação (ANPED) e o Encontro Nacional de Pesquisa em Educação em Ciências (ENPEC) (Proença, et al. 2019). Além disso, o Encontro de Pesquisa em Ensino de Física (EPEF), da Sociedade Brasileira de Física, inaugurou em 2018 a linha temática Equidade, Inclusão, Diversidade e Estudos Culturais e o Ensino de Física e contou com uma mesa redonda intitulada Questões de Gênero, Minorias e a Pesquisa em Ensino de Física 5 .

5 http://www.sbfisica.org.br/ epef/xvii/index.php/pt/, acesso em 28 de fevereiro de 2020. 
Na pesquisa internacional, a situação é bastante diferente. Em um artigo publicado há mais de uma década, Brotman e Moore (2008) já apontavam os avanços ocorridos "nos últimos 30 anos" com relação à redução da lacuna de gênero nas ciências. Nesse artigo, as autoras revisam quatro temas que caracterizam a literatura especializada sobre questões de gênero: (i) Equidade e acesso; (ii) Currículo e pedagogia; (iii) Natureza e cultura da ciência; (iv) Identidade. O primeiro tema, "Equidade e acesso", descreve as disparidades e desigualdades de gênero na sala de aula e enfatizam a importância de fornecer às meninas equidade de oportunidades científicas. O segundo tema, "Currículo e pedagogia", é inspirado nos trabalhos de Carol Gilligan (1983) e de Mary Belenky, Blythe Clinchy, Nancy Goldberger e Jill Tarule (1986) e enfatiza a necessidade de mudar o currículo e a pedagogia da sala de aula de ciências de modo a incluir as experiências, interesses e estilos de aprendizagem das meninas. O terceiro tema, "Natureza e cultura da ciência", está relacionado à crítica feminista da ciência, articulada por autoras como Evelyn Fox Keller (1982), Sandra Harding (1992) e Donna Haraway (1988), e enfatiza a necessidade de reconstruir o modo como a ciência é retratada, vista e definida tanto na escola como na sociedade. Por fim, o quarto tema, "Identidade", evita oposições binárias que focam no gênero e ignoram a diversidade existente dentro de cada grupo e enfatiza a necessidade de ajudar as meninas a incorporar a ciência como uma componente de suas identidades, interseccionando gênero com outros marcadores socioculturais como raça, etnia e classe social.

Atualmente, há um amploleque de pontos de vista da teoria feminista que decorrem de diferentes ideologias (Scantlebury et al., 2010). De acordo com Sinnes e Løken (2014), essas diferentes perspectivas podem ser agrupadas em três abordagens que tornam explícitos certos pressupostos de como o gênero impacta a aprendizagem de ciências: (i) Feminismo da igualdade; (ii) Feminismo da diferença; e (iii) Feminismo pós-moderno ${ }^{6}$. O Feminismo da igualdade, também referido como "empirismo feminista" (Harding, 1986), pressupõe que não existem diferenças na maneira como meninos e meninas se engajam nas ciências. De acordo com essa perspectiva, homens e mulheres são iguais e, portanto, deveriam ter as mesmas oportunidades para seguir carreiras científicas. Já o Feminismo da diferença ${ }^{7}$ afirma que, seja por questões biológicas ou culturais, as mulheres desenvolveram o que a sociedade chama de características "femininas" e possuem habilidades particulares que precisam ser reconhecidas e valorizadas. Segundo

6 Neste trabalho apresentamos as definições dos Feminismos e suas implicações para o Ensino de ciências a partir da perspectiva de Sinnes e Loken (2014). No entanto, existem trabalhos que apresentarão de forma diferente tais definições e implicações, como por exemplo, Barton (1998), Brickhouse (2001) e Howes (2002).

7 Neste artigo apresentamos uma definição do Feminismo da diferença pautada principalmente na literatura norte-americana, no entanto, como apresentado em Costa (2002), a perspectiva da diferença também é discutida e situada pelas filosofas e sociólogas latino-americanas. Em linhas gerais, o Feminismo da diferença passou por três grandes transições teóricas. Primeiramente, a noção da diferença se apoiava exclusivamente num "hiato radical entre mulheres e homens" (Costa, 2002, p. 79). A segunda transição defendia que existia diferenças entre mulheres e homens e também entre as próprias mulheres. Essa percepção surgiu inicialmente entre as mulheres de cor, lésbicas e feministas do Terceiro Mundo. Já a terceira transição parte de uma elaboração da anterior que enfatizava as "diferenças de intersecções múltiplas" (Costa, 2002, p. 80) como raça, classe, orientação sexual, dentro outros construtos sociais. 
essa perspectiva, faltaria à ciência certos atributos femininos que poderiam aprimorar algumas práticas científicas. Finalmente, o Feminismo pós-moderno afirma que a "categoria mulher" não é neutra nem representa uma essência, mas é algo socialmente construído. De acordo com essa perspectiva, só podemos enxergar o mundo a partir de nossa perspectiva pessoal e, portanto, todo conhecimento é situado - a exclusão das mulheres na ciência faz com que muitas vozes não sejam ouvidas.

No presente texto, apresentamos as maneiras de conhecer das mulheres, conforme a análise de Belenky et al. (1986), como possível referencial teórico para os estudos de gênero na educação em ciências. Essa abordagem se situa no tema Currículo e Pedagogia, segundo a classificação de Brotman e Moore (2008), e adota a perspectiva do Feminismo da diferença, conforme a análise de Sinnes e Løken (2014). O objetivo do presente artigo é contribuir para o preenchimento de uma lacuna identificada na literatura sobre gênero, conforme apontada na revisão de Heerdt et al. (2018). De acordo com as autoras, das 90 revistas consultadas em 10 anos de pesquisa, apenas 01 dos 34 artigos analisados (Cruz, 2014) apresenta "um texto de base teórica para os estudos de gênero na Educação Científica" (Heerdt et al., 2018, p. 229). Assim como qualquer referencial teórico, o quadro analítico fornecido por Belenky et al. (1986) possui tanto virtudes quanto limitações. No entanto, acreditamos que as cinco perspectivas descritas pelas autoras têm o potencial de contribuir para o planejamento de intervenções de sala de aula que busquem a equidade de gênero no ensino de ciências.

\section{Cinco Perspectivas Relativas ao Desenvolvimento das Mulheres}

Em sua obra "Women's ways of knowing: The development of self, voice, and mind”, Belenky et al. (1986) analisam as maneiras de conhecer das mulheres e descrevem cinco diferentes perspectivas através das quais as mulheres veem a realidade e tiram conclusões sobre verdade, conhecimento e realidade. Esse estudo se enquadra nas pesquisas sobre "crenças epistemológicas", as quais têm mostrado que as crenças pessoais sobre a natureza do conhecimento desempenham um papel fundamental no desenvolvimento intelectual e na aprendizagem de assuntos específicos (Khine \& Hayes, 2010). De acordo com as autoras, nossas suposições sobre a natureza da verdade e da realidade e as origens do conhecimento moldam a forma como vemos o mundo e a nós mesmos como participantes dele: "Eles afetam nossa definição de nós mesmos, a maneira como interagimos com outras pessoas, nossa persona pública e privada, nosso senso de controle sobre os eventos da vida, nossas visões de ensino e aprendizagem e nossas concepções de moralidade" (Belenky et al., 1986, p. 3). Ao mostrar como as concepções das mulheres sobre elas próprias e suas maneiras de conhecer estão entrelaçadas, as autoras descrevem como mulheres lutam para afirmar o poder de suas mentes e como a família e a escola (duas instituições dedicadas ao desenvolvimento humano) promovem e dificultam o desenvolvimento das mulheres.

As perspectivas descritas por Belenky et al. (1986) são traçadas a partir de entrevistas extensivas (de 2 a 5 horas de duração) realizadas com 135 mulheres 
norte-americanas de nove instituições acadêmicas e agências sociais, com diferentes idades, níveis de instrução, classes sociais e etnias, de áreas rurais e urbanas. No caso das instituições acadêmicas, as participantes (90 no total) foram escolhidas através de indicações das instituições das quais faziam parte. Foram selecionadas mulheres consideradas representativas de uma diversidade de idades, interesses principais, grau de envolvimento ou alienação da instituição e nível de desempenho acadêmico. No caso das agências sociais, referidas pelas autoras como "faculdades invisíveis" (Belenky et al., 1986, p. 12), foram selecionadas 45 mulheres ligadas ao serviço de assistência à maternidade de zonas rurais bastante pobres. Assim, ao incluir um número considerável de mulheres desfavorecidas e esquecidas, cujos modos de conhecer, transformações identitárias e perspectivas morais raramente eram examinados por pesquisadores acadêmicos na época em que o estudo foi desenvolvido, as autoras puderam explorar as estratégias para promover a educação e o desenvolvimento de mulheres que são praticadas fora do contexto escolar, em uma instituição administrada exclusivamente por mulheres. $\mathrm{O}$ grupo heterogêneo de mulheres que participaram desse estudo proporcionou às autoras explorarem a interseccionalidade de diferentes construtos sociais e suas implicações nas experiências relacionadas aos processos psicológicos, educacionais e identidades sociais das mulheres entrevistadas (Ireland et al., 2018).

As entrevistas se basearam nos trabalhos anteriores de William Perry (1970), Lawrence Kohlberg (1981) e Carol Gilligan (1983) e buscaram explorar as experiências e problemas das mulheres enquanto aprendizes e pessoas capazes de saber, bem como revisar suas histórias passadas de mudanças de concepção sobre si mesmas e de relacionamento com outras pessoas. Após a etapa de análise das transcrições, as autoras agruparam as perspectivas das mulheres entrevistadas em cinco grandes categorias epistemológicas: Silêncio; Conhecimento recebido; Conhecimento subjetivo; Conhecimento processual; e Conhecimento construído. O Silêncio é a posição na qual as mulheres se sentem intelectualmente incapazes e sem voz e estão sujeitas ao domínio de autoridades externas - geralmente homens (pais, maridos, professores, etc.). O Conhecimento recebido é a perspectiva na qual as mulheres se veem como sendo capazes de receber, e até mesmo reproduzir, o conhecimento recebido de autoridades externas, mas não de construir elas próprias o conhecimento. O Conhecimento subjetivo é a perspectiva na qual a verdade e o conhecimento são concebidos como sendo pessoais, privados e subjetivamente intuídos. O Conhecimento processual é a perspectiva na qual as mulheres buscam aprender a aplicar procedimentos fixos para obter e comunicar conhecimentos. Por fim, o Conhecimento construído é a posição na qual as mulheres percebem todo o conhecimento como sendo contextual, se veem como construtoras de conhecimento e valorizam tanto as estratégias subjetivas como as objetivas para conhecer.

É importante destacar que as autoras reconhecem que as cinco maneiras de conhecer, por elas descritas, não devem ser entendidas como categorias fixas, exaustivas ou universais. Essas perspectivas representam categorias abstratas que não podem capturar adequadamente a complexidade e a singularidade do pensamento e da vida das 
mulheres. Também enfatizam o fato de que categorias similares podem ser encontradas no pensamento de homens. Além disso, as autoras também reconhecem que outras pessoas podem organizar suas observações de maneira distinta. Dado a diversidade contextual incluída neste estudo em termos de idades, circunstâncias de vida e origens socioculturais, traçar um caminho evolutivo universal se torna uma tarefa bem menos óbvia. Nesse sentido, as autoras deixam em aberto se essas cinco perspectivas apresentam a qualidade de "estágios" no desenvolvimento das mulheres (Belenky et al., 1986, p. 15). Responder como e por que as mulheres mudam de uma maneira de conhecer para outra, como muitas das mulheres entrevistadas fizeram em diferentes pontos em suas vidas, é certamente uma questão importante, porém complexa e não pode ser adequadamente respondida a partir das observações feitas pelas autoras, já que grande parte dos dados é limitada a uma única sessão de entrevista.

\section{Silêncio}

A primeira perspectiva fornecida pelas autoras é o Silêncio. Embora apenas algumas poucas mulheres enxergavam o mundo a partir dessa perspectiva na época das entrevistas, outras, tendo superado essa categoria, forneciam um panorama em retrospectiva. O termo Silêncio serve para designar a falta de voz de mulheres nessa posição. Elas cresceram em isolamento, tendo poucas amizades na infância e pouco diálogo com os membros da família. As mulheres silenciosas, ou "silenciadas" (Belenky, 1996; Clinchy, 2002), estão entre as mais jovens e as mais privadas social, econômica e educacionalmente de todas as entrevistadas, sendo a maioria das agências sociais de apoio à maternidade. O Silêncio surge de um cenário de pobreza, isolamento, subordinação, rejeição e extrema violência, incluindo casos de abuso sexual e incesto. Essa posição representa um extremo na negação do "eu" e na dependência de autoridades externas para direcionamentos. Para a maioria das mulheres nessa posição, as palavras são percebidas como "armas" (Belenky et al., 1986, p. 24), sendo utilizadas para separar e diminuir pessoas e não para conectá-las e empoderá-las.

As mulheres silenciadas não acreditam na sua capacidade em aprender com base nas suas experiências. Elas se sentem dependentes, inferiores e impotentes frente a indivíduos que elas consideram como autoridades externas, e a nossa cultura, muitas vezes, reforça essas noções. Essas autoridades são imprevisíveis, pois não costumam explicar o que essas mulheres devem fazer, mas esperam que elas adivinhem. Afirmam o que é certo sem nunca explicar o porquê das afirmações. Como consequência, as mulheres se tornam submissas e obedientes às autoridades, pois acreditam que dessa forma conseguem evitar problemas e garantir a sua sobrevivência. Saber o porquê das coisas passa a ser considerado como algo sem importância ou até mesmo impossível. A ausência de diálogo e da troca de experiências, desde a infância, faz com que essas mulheres permanecem isoladas de outros e de si mesmas, tornando-se inseguras de suas próprias capacidades intelectuais. Elas passam a acreditar que, assim como as crianças, as mulheres devem ser vistas, mas não ouvidas. A escola, que deveria ser um espaço para 
elas se desenvolverem, acaba reforçando a crença de que elas são inferiores e impotentes.

De acordo com Clinchy (2002), diversas mulheres altamente instruídas já relataram adotar a perspectiva do Silêncio. Embora elas não se consideram aprisionadas no Silêncio (com "S" maiúsculo), essas mulheres se veem frequentemente em situações nas quais são silenciadas (com "s" minúsculo). Muitas delas se sentem silenciadas por colegas homens em sala de aula. Elas sentem medo de expor sua opinião, por não se sentirem inteligentes o suficiente ou por não saberem como se expressar sem serem julgadas, e então elas se calam. Para muitas mulheres, o silêncio não é uma questão de ser incapaz de reivindicar um espaço e um tempo para entrar em uma conversa, mas sim de não descobrir formas de discurso para expressar significados e conseguir aprovação dos outros. Obviamente, esse tipo de silêncio descrito por Clinchy (2002) se restringe a uma situação bastante particular, embora não incomum, de mulheres que foram capazes de conceber estratégias para superar situações de silenciamento. Já o Silêncio profundo vivido pelas mulheres das agências sociais permeia toda a sua vida e representa um estado bem menos tratável, embora não irreversível, de não desenvolvimento intelectual.

\section{Conhecimento Recebido}

A segunda perspectiva descrita por Belenky et al. (1986) é o Conhecimento recebido. Muitas adolescentes das agências sociais relataram que passaram a se ver como pessoas capazes de saber somente quando se tornaram mães. Elas precisavam saber como cuidar de seus bebês e as agentes sociais pareciam ter todas as respostas. As mulheres que seguem a perspectiva do Conhecimento recebido se veem capazes de aprender e de reproduzir o conhecimento. No entanto, elas assumem que existe uma única Verdade (com "V" maiúsculo) que é inequívoca, absoluta, universalmente válida, externa e está sob posse de autoridades. Elas veem o mundo em termos de certo e errado, verdadeiro e falso, bom e mau - para elas não existem ambiguidades (Clinchy, 2002). Ao contrário das mulheres silenciadas, as recebedoras de conhecimento acreditam que as palavras são centrais para adquirir conhecimento e se sentem confiantes nas suas capacidades de reter informações. No entanto, elas veem o conhecimento como algo a ser armazenado e reproduzido, mas nunca como algo a ser questionado. Nessa perspectiva, a aprendizagem na escola ocorre quando elas recebem e reproduzem o conhecimento fornecido pelo(a) professor(a). A exigência para realizarem trabalhos originais as deixam confusas, fazendo com que elas se sintam incapazes. Para essas mulheres, não existe dualismos e paradoxos. Elas acreditam que para cada pergunta existe apenas uma resposta correta e não existe meio termo. Fatos são a Verdade enquanto que opiniões não o são. Por isso, não avaliam ideias, apenas as recebem tal como elas são fornecidas.

As mulheres do Conhecimento recebido acreditam que as autoridades também não são capazes de construir o conhecimento - elas apenas recebem a verdade de autoridades ainda maiores. Assim como as mulheres silenciadas, elas precisam também de autoridades externas para obter autoconhecimento e para guiá-las em suas trajetórias. Elas contam com essas autoridades para lhes dizer o que é certo, quem elas são e no que elas 
devem acreditar (Clinchy, 1990). Não é de se estranhar que esse tipo de comportamento exista, tendo em vista que a sociedade atribui à mulher um status subordinado, devendo elas ouvir o que os homens têm a dizer. As mulheres que se enquadram nessa posição acreditam que seus amigos possuem as mesmas experiências e pensamentos que elas e normalmente não percebem quando os seus pensamentos estão mudando para ficarem parecidos com os de suas amizades. No entanto, são esses tipos de relacionamentos que proporcionam às mulheres oportunidades de conhecerem a si mesmas e perceberem suas capacidades de aprender. Outra forma é ajudando, ensinando e compreendendo outras pessoas. Como elas tendem a moldar quem elas são conforme o que as outras pessoas esperam delas, estas acabam tendo uma influência considerável tanto para diminuir como para empoderar, podendo ajudá-las a acreditarem nelas mesmas (especialmente com relação à criação de seus filhos).

Em um artigo intitulado Issues of Genderin Teaching and Learning, Blythe McVicker Clinchy (1990), uma das autoras de Women's Ways of Knowing, afirmou ter aprendido com as mulheres entrevistadas a sentir um respeito genuíno pelo Conhecimento recebido. Elas a ensinaram a ver as virtudes dessa posição. Ela passou a ver o Conhecimento recebido como uma conquista real e não como algo a ser simplesmente superado, como a "catapora" ou a "adolescência" (Clinchy, 1990, p. 60). No entanto, enquanto professora, ela deseja que as suas alunas da faculdade possam ir além dessa posição. Isso porque as alunas que contam exclusivamente com o Conhecimento recebido não estão, num certo sentido, realmente pensando - suas ideias já vem prontas do(a) professor(a). Elas não utilizam qualquer procedimento sistemático para desenvolver novas ideias ou testar a validade de ideias. Ainda assim, por mais limitado que o Conhecimento recebido possa parecer, é fácil perceber como cada um de nós reverte a essa posição toda vez que encontramos algo novo, complexo e incompreensível. No final, acabamos confiando nos especialistas para nos dizer o que esse algo novo realmente significa.

\section{Conhecimento Subjetivo}

A terceira perspectiva fornecida pelas autoras é o Conhecimento subjetivo. Num certo sentido, o Conhecimento subjetivo, ou "subjetivismo" (Belenky et al., 1986), é o oposto do Conhecimento recebido (Clinchy, 2002). Para as mulheres subjetivistas, a verdade (com "v" minúsculo) é algo pessoal, de modo que todas as opiniões são igualmente válidas. Enquanto as mulheres silenciadas e recebedoras de conhecimento consideram que existe uma "Verdade" única e absoluta que é válida para todos, as mulheres subjetivistas consideram que a verdade é relativa - cada uma tem a sua verdade. As subjetivistas olham para dentro delas mesmas em busca do conhecimento. Para elas, a verdade é visceral - é algo que vem de dentro, que vem do coração. Diferentemente das recebedoras de conhecimento, as mulheres subjetivistas costumam ser bastante suspeitas com relação às informações fornecidas por autoridades externas. Elas confiam muito mais em seus instintos, em suas intuições, em sua voz interna - elas são suas próprias autoridades. 
Ao se enxergarem como sendo suas próprias autoridades, as mulheres subjetivistas se sentem mais seguras em relação as suas ideias, intuições, sentimentos e comportamentos, o que as torna mais independentes. Essa forma de conhecer é valorizada em muitas culturas não ocidentais, porém, é desvalorizada em culturas onde prevalece o racionalismo e o pensamento científico. Quase metade das 135 mulheres entrevistadas se enquadravam nessa perspectiva e eram oriundas de famílias menos favorecidas. As subjetivistas consideram que o processo de escolarização é alienante e irrelevante. Elas passam a adotar a perspectiva do Conhecimento subjetivo devido a experiências pessoais fora da escola. Em sala de aula, os professores a veem como alguém arbitrário, emocional, excessivamente pessoal e rebelde. Elas confiam mais nas informações fornecidas pela experiência em primeira mão de pessoas próximas (mãe, irmãs, etc.) do que na informação de segunda mão fornecida por autoridades - afinal de contas, as experiências das pessoas não podem estar erradas! Em vez de basear-se em palavras ou inferências, as estudantes subjetivistas baseiam-se na apreensão direta da realidade.

Para avaliar discordâncias, as subjetivistas usam a sua experiência e suas intuições na hora de tomar uma decisão. Quando são contrariadas, elas parecem ser menos preocupadas em convencer os outros a aceitarem a sua opinião ou ponto de vista. Para elas, a experiência de vida de cada uma proporciona uma visão particular da realidade, e essa visão, segundo as subjetivistas, não deve ser imposta para as outras pessoas. Assim, resolver discordâncias pode ser uma tarefa árdua e desagradável e pode até mesmo prejudicar relacionamentos. Elas sentem que não precisam aceitar as ideias de especialistas em um determinado assunto. Desconfiam da lógica, da análise, da abstração e até da própria linguagem, pois consideram que tais métodos são de um território que pertence aos homens. Elas não rejeitam esse conhecimento, mas possuem certo ceticismo, pois acreditam que essa forma de pensar não é feminina (ou mesmo humana). Elas traçam uma linha nítida entre conhecimento intuitivo e o que elas assumem como sendo pensamento abstrato e impessoal, que pode prejudicar a sua capacidade de sentir. Assim, elas adotam uma atitude antirracional como forma de valorizar a intuição enquanto abordagem segura e frutífera para chegar a sua verdade.

\section{Conhecimento Processual}

A quarta maneira de conhecer delineada por Belenky et al. (1986) éo Conhecimento processual. Essa posição epistemológica indica que o conhecimento não depende da intuição ou das informações coletadas do conteúdo, mas requer pensamento consciente e sistemático (Khine \& Hayes, 2010). O conhecer processual é a “voz da razão" (Belenky et al., 1986, p. 87). Para as mulheres nessa posição, o conhecimento não consiste de fatos a serem armazenados ou de resíduos estáticos da experiência direta - conhecer é um processo e requer trabalho (Clinchy, 2002). Embora não exista, nessa perspectiva, uma única resposta certa para as questões, nem todas as interpretações são igualmente válidas. $\mathrm{O}$ ato de conhecer demanda a aplicação de procedimentos para comparar, contrastar e 
construir interpretações, e a qualidade do conhecimento obtido depende da habilidade daquele que conhece. Para desenvolver essa perspectiva é necessária a presença de autoridades benignas, que usem as palavras não como um instrumento de opressão, mas como um auxílio à compreensão (Belenky et al., 1986). São essas autoridades que nos ajudam a construir procedimentos para entender e avaliar ideias (Clinchy, 1990). O Conhecimento processual é encontrado em duas formas distintas: o Conhecimento separado e o Conhecimento conectado. Em suma, o Conhecimento separado é crítico e objetivo enquanto que o Conhecimento conectado é mais empático e receptivo (Khine \& Hayes, 2010).

\section{Conhecimento Separado}

O Conhecimento separado é o modo de discurso envolvido em atividades como o pensamento crítico, o método científico e a análise textual (Clinchy, 1989). A característica principal do Conhecimento separado é o desapego. As mulheres que adotam essa perspectiva buscam manter-se distante do objeto que está sendo analisado. O Conhecimento separado adota um tom competitivo que envolve argumento, debate, bancar o advogado do diabo ou apontar furos na posição dos outros. As conhecedoras separadas são aquelas que duvidam, que procuram falhas no raciocínio, que examinam argumentos com um olhar crítico, adotando uma postura impessoal (Khine \& Hayes, 2010). Elas procuram rigorosamente deixar de lado seus próprios sentimentos na hora de avaliar uma proposta ou ideia (Belenky et al., 1986). O Conhecimento separado requer o emprego de regras e procedimentos fixos para garantir um julgamento imparcial - ele busca ser analítico e objetivo. As mulheres dessa posição não enxergam seus ouvintes como um aliado na conversa, mas sim como um avaliador hostil. O objetivo do Conhecimento separado é convencer e ser convencido (Khine \& Hayes, 2010).

O Conhecimento separado é obviamente de grande importância e tem sido adotado em todas as nossas disciplinas e vocações (Clinchy, 1989). Ele nos permite criticar nosso próprio pensamento e o pensamento de outros. Sem ele, estaríamos à mercê de autoridades que buscam nos dizer em que acreditar. No entanto, muitas das mulheres entrevistaram relataram que, ao utilizar o Conhecimento separado, sentiam que suas vozes eram ecos das vozes de outras pessoas, consideradas como autoridades. Elas não se sentiam pessoalmente envolvidas na busca pelo conhecimento e muitas delas se sentiam uma fraude e ansiavam por encontrar uma voz própria - uma que fosse mais integrada e original (Belenky et al., 1986). Apesar de ser uma forma poderosa de conhecer, o Conhecimento separado não é a única forma de Conhecimento processual utilizado pelas mulheres. Muitas delas preferem seguir outra rota - uma que envolva adotar uma perspectiva que seja menos competitiva e imparcial e que seja mais colaborativa e pessoal. 


\section{Conhecimento Conectado}

O Conhecimento conectado apresenta características bastante distintas do Conhecimento separado. Em vez de adotar um tom competitivo, tomando uma posição contrária a de outras pessoas, as conhecedoras conectadas tentam se aliar à posição dos outros, mesmo quando elas discordam dessa posição (Clinchy, 1989). Elas buscam entender a posição em vez de avaliar ou testar a sua validade. Nessa perspectiva, para entender o que uma pessoa está dizendo, é preciso adotar os próprios termos dela. A principal característica do Conhecimento conectado é o apego. Em vez de se opor às ideias de uma pessoa, as conhecedoras conectadas buscam colaborar com ela. Elas buscam o entendimento e o significado e usam os seus sentimentos para iluminar os pensamentos (Belenky et al., 1986). As conhecedoras conectadas não são observadoras imparciais. Ao contrário, elas deliberadamente se colocam em favor daquilo que elas estão examinando. Elas se colocam no lugar das outras pessoas e tentam entender seu ponto de vista, por que elas pensam o que pensam, por que acreditam que estão certas e por que isso faz sentido (Clinchy, 1989). Ele envolve conexões mais profundas com o objeto a ser compreendido. Em vez de perguntar se algo está certo, as mulheres conectadas tendem a perguntar o que esse algo significa. O objetivo do Conhecimento conectado é entender e ser entendido (Khine \& Hayes, 2010).

Está claro para as autoras que muitas das mulheres entrevistadas têm uma tendência ao Conhecimento conectado. O que antes era visto pela pesquisa acadêmica como uma deficiência ou incapacidade de se engajar em pensamento crítico, passou a ser visto, após a publicação de Women's ways of knowing, como uma maneira diferente e legítima de pensar. Se a voz do Conhecimento separado é o argumento, a voz do Conhecimento conectado é a narrativa. Muitas mulheres passam boa parte do seu tempo compartilhando histórias de suas experiências. Este fato pode ajudar a explicar por que muitos estudos sobre desenvolvimento intelectual realizado com mulheres universitárias mostram que o maior crescimento intelectual ocorre durante o primeiro ano letivo (Clinchy, 1989). Assim, o Conhecimento conectado não é apenas uma maneira de conhecer, mas também uma maneira de crescer, possibilitando novas formas de ser. No entanto, o Conhecimento conectado é desvalorizado pela sociedade, assim como a pessoa que o utiliza. Na maioria das instituições, o que predomina é o Conhecimento separado e muitas mulheres precisam se adaptar a essa posição para obter aprovação.

\section{Conhecimento Construído}

A quinta maneira de conhecer delineada por Belenky et al. (1986) é o Conhecimento construído. Essa perspectiva epistemológica é resultado da integração entre o Conhecimento separado e Conhecimento conectado. Dentre as entrevistadas, essa posição foi encontrada em mulheres de meia idade, com nível de pós-graduação, relativamente privilegiadas e ativas tanto na vida profissional como na vida comunitária. A principal característica dessa maneira de conhecer éa crença de que todo conhecimento é construído e de que "o conhecedor é parte íntima do conhecido" (Belenky et al., 1986, 
p. 137). As mulheres construtivistas possuem consciência de inventar a realidade. Elas assumem a complexidade e a ambiguidade das coisas e tratam as respostas certas como casos especiais. Para elas, dar uma única resposta não é suficiente ou não é a única forma - existe sempre mais de uma possibilidade. Elas reconhecem que são responsáveis pela construção do conhecimento e entendem que é seu dever considerar construções alternativas. Enquanto as conhecedoras processuais estão sujeitas a procedimentos fixos, as construtoras de conhecimento estão no controle dos procedimentos. Elas buscam equilibrar interesses intelectuais, criativos, sociais e práticos, sem ter que abrir mão de um em prol do outro. Diálogo e equilíbrio são palavras chave nessa perspectiva.

Com relação às ciências, as construtoras de conhecimento têm consciência de que as teorias não expressam a "Verdade", mas são modelos para aproximar a experiência os modelos são sempre mais simples que o mundo real. Assim, elas não acreditam que exista um experimento crucial ou um argumento perfeito e insuperável que resolva um determinado problema. Para elas, perguntas e respostas variam ao longo da história, entre culturas, de disciplina para disciplina e de indivíduo para indivíduo. As construtoras de conhecimento procuram evitar generalizações sobre o que deve ser feito ou sobre o que é certo ou errado. Questionar é um requisito central para o Conhecimento construído. Para elas, o confronto de ideias e brigas familiares não é uma questão de dominação e controle, mas de conflito entre visões de mundo. As mulheres construtivistas conseguem fazer conexões entre seus interesses e vida profissional. Entender a si mesmo é um passo fundamental para conseguir desenvolver o que as autoras chamam de "a voz da integração" (Belenky et al., 1986, p. 131). Quando há conflito entre sentimentos e pensamentos, as mulheres construtivistas buscam estabelecer um diálogo entre os dois (Clinchy, 2002).

As mulheres construtivistas são pessoas articuladas e reflexivas. Elas não querem mais negar ou reprimir quem elas são para evitar conflitos, facilitar suas vidas ou para se sair bem no trabalho. Elas querem viver plenamente cada papel que elas desempenham (como mães, educadoras, filhas, amigas, etc.) sem abdicar de um papel em prol de outro. Elas se preocupam com questões de inclusão e exclusão, separação e conexão e lutam para equilibrar os extremos de suas vidas e encontrar a própria voz (Belenky et al., 1986). Elas desejam que suas vozes e ações façam diferença na vida de outras pessoas e no mundo. Para falar em uma voz única e autêntica, as mulheres construtivistas entendem que precisam pensar fora dos referenciais e sistemas fornecidos por autoridades externas - mover-se para fora do que é dado - para então criar os seus próprios referenciais. Nesse sentido, o Conhecimento construído começa como um esforço em reivindicar a si próprio na tentativa de integrar o conhecimento que elas sentem que são pessoalmente importantes com o conhecimento que elas aprenderam com as outras pessoas. A busca pelo "eu" e por uma voz própria desempenha um papel fundamental nas transformações das maneiras de conhecer das mulheres. 


\section{Maneiras de Conhecer e a Questão de Gênero}

É importante enfatizar que as diferentes maneiras de conhecer delineadas por Belenky et al. (1986) se baseiam inteiramente em entrevistas realizadas com mulheres. Isto não quer dizer que as cinco posições descritas pelas autoras se aplicam exclusivamente a mulheres. No entanto, as autoras suspeitam que essas posições podem assumir um diferente tom quando aplicadas a homens (Clinchy, 1990). Por exemplo, quando as mulheres subjetivistas expõem as suas ideias, elas tendem a apresentá-las num tom humilde, autodepreciativo, diferentemente dos conhecedores "multiplistas" da pesquisa de Perry (1970). Nesse estudo, realizado com estudantes homens da Universidade de Harvard, o autor identificou quatro posições distintas: dualismo, multiplicidade, relativismo e comprometimento dentro do relativismo. Assim como as subjetivistas de Belenky e suas colegas, os multiplistas de Perry também acreditam que não existem respostas que sejam absolutamente certas e entendem que a verdade é algo pessoal - portanto, todas as opiniões são igualmente válidas. No entanto, os multiplistas entendem que têm direito a sua própria opinião e que nenhum professor pode lhes dizer o que é certo. Já as subjetivistas tendem a apresentar suas ideias como sendo apenas suas opiniões e achariam errado impor o que elas pensam a qualquer outra pessoa.

Importantes diferenças também podem ser encontradas com relação ao Conhecimento processual. Em um artigo intitulado The Development of Thoughtfulness in College Women, Clinchy (1989) mencionou um estudo exploratório no qual homens e mulheres foram entrevistados. Nesse estudo, o Conhecimento separado é visto pelos homens como algo positivo, que pode ajudar as pessoas a pensar com mais clareza. Já as mulheres veem o Conhecimento separado como um jogo de soma-zero, em que apenas um dos lados pode vencer o debate. Assim como as mulheres se sentem desconfortáveis com o Conhecimento separado, os homens também relatam ter dificuldades com o Conhecimento conectado. Em outro artigo, publicado dez anos mais tarde, Galotti et al. (1999) desenvolveram um instrumento chamado The Attitudes Toward Thinking and Learning Survey (ATTLS). Esse instrumento contém 50 itens com afirmações que ilustram maneiras de conhecer separadas e conectadas. Em uma série de quatro estudos, realizados com estudantes universitários de ambos os sexos, as autoras mostraram que as pontuações nas duas escalas não estão correlacionadas, o que significa que as duas posições são independentes. Além disso, as autoras reportaram que as mulheres consistentemente concordaram mais com as afirmações do Conhecimento conectado do que com as afirmações do Conhecimento separado e que os homens mostraram uma pequena, mas não significativa, diferença a favor das afirmações do Conhecimento separado.

É importante destacar que as próprias autoras do Women's Ways of Knowing admitem que os resultados mencionados acima não implicam que todas as mulheres, $\mathrm{e}$ somente as mulheres, são conhecedoras conectadas, e que todos os homens, e somente os homens, são conhecedores separados. Da mesma forma, dizer que as mulheres, em geral, demonstram certa inclinação pelo Conhecimento conectado não significa 
dizer que elas não conseguem ou não querem pensar criticamente. $\mathrm{O}$ que as autoras afirmam é que muitas mulheres preferem pensar "com" outras pessoas em vez de pensar "contra" elas (Clinchy, 1989). É importante destacar que as autoras não se opõem ao cultivo do Conhecimento separado na academia e reconhecem que é importante ensinar as habilidades deste tipo de conhecimento. O que elas se opõem é contra um sistema educacional que coloca ênfase quase que exclusivamente no Conhecimento separado e falha em reconhecer, quanto mais respeitar e nutrir, as habilidades do Conhecimento conectado. Sugestões para reverter tal situação serão apresentadas na próxima seção.

\section{Maneiras de Conhecer e o Ensino de Ciências}

As maneiras de conhecer descritas por Belenky et al. (1986) têm sérias implicações para a sala de aula de ciências. Sejam em escolas públicas ou privadas, essas diferentes vozes estão sempre presentes e se manifestam de diferentes formas. No caso do Silêncio, não é raro encontrar adolescentes que não acreditam em sua própria capacidade de aprender ciências. Já as estudantes recebedoras de conhecimento são aquelas sentadas, com a caneta em mãos, prontas para copiar as "Verdades" fornecidas pelos professores. Costumam querer saber quais tópicos exatamente cairão na prova ou quantas páginas devem constar no relatório das aulas experimentais. As estudantes subjetivistas, por sua vez, são aquelas que não valorizam o conhecimento científico ensinado na escola, pois consideram que a ciência escolar não tem relação qualquer com a vida prática. As conhecedoras subjetivistas costumam fazer perguntas do tipo "Por que eu devo aprender esse conteúdo?" ou "Quando eu vou usar isso na minha vida?".

Quanto as estudantes processadoras de conhecimento, é possível encontrá-las nas duas formas. As alunas cuja postura epistemológica é a do Conhecimento separado são aquelas que os professores de ciência normalmente consideram como alunas ideais: sabem aplicar o conhecimento científico e gostam de pensar criticamente, questionando a posição de seus colegas. Já as alunas com a postura epistemológica do Conhecimento conectado são mais passionais e tentam se relacionar com o objeto de estudo. Em geral, quem assume esta postura é menos competitiva e mais colaborativa e gosta de ouvir com atenção o que os seus colegas têm a dizer. Finalmente, as alunas construtoras de conhecimento são aquelas que têm consciência de que as teorias científicas não são fatos, mas sim modelos - representações simplificadas da realidade. Para elas, a ciência é muito rica e poderosa, mas não é superior a qualquer outra disciplina ou forma de conhecimento. A seguir, mostramos como as diferentes posições epistemológicas de Belenky et al. (1986) têm sido utilizada nas pesquisas em educação em ciências e como elas podem ser usadas para planejar o ensino em sala de aula.

\section{Implicações para a Pesquisa em Educação em Ciências}

A primeira parte dessa seção não tem a pretensão de apresentar uma revisão extensiva sobre o tema. Para um rápido panorama de como o trabalho de Belenky et al. (1986) tem sido usado em pesquisas na área de Educação em Ciências, foram 
levantados alguns artigos nas revistas Science Education e International Journal of Science Education. A escolha desses periódicos se justifica por se tratarem de revistas de grande impacto na área de Educação em Ciências. Ao investigar diferenças de gênero nas experiências, interesses e atitudes de estudantes com relação às ciências, Jones, Howe e Rua (2000) aplicaram um instrumento a 437 crianças do sexto ano de cinco escolas norte-americanas. Em geral, os resultados apontaram diferenças de gênero em favor dos meninos. Para lidar com alguns resultados "inesperados", no entanto, as autoras recorreram à noção de Conhecimento conectado, conforme definido por Belenky et al. (1986). Dentre os resultados inesperados estão meninos que veem a ciência como algo "destrutivo e perigoso" e que "cria problemas para a sociedade" (Jones et al., 2000, p. 190). Além disso, muitos relataram ter interesse em saber mais como a ciência e a tecnologia podem ajudar pessoas desabilitadas. As autoras também fazem referência ao Conhecimento separado para explicar resultados como o de que a maioria dos alunos acreditam que a ciência é mais adequada para meninos.

Ao analisar a influência de histórias pessoais na formação da identidade de professores de ciência com orientação à investigação, Eick e Reed (2001) usam as noções de Conhecimento construído e Conhecimento recebido de Belenky et al. (1986) para interpretar como dois sujeitos de pesquisa, Shery and Carey, lidam com atividades de investigação estruturada que aprenderam no programa de formação de professores. De acordo com os autores, Shery se identifica como uma "construtora de conhecimento" e vê a verdade mais como "uma questão de história pessoal, circunstância e tempo" (Eick \& Reed, 2001). Já Carey se identifica mais como uma "recebedora de conhecimento", se baseando fortemente em práticas tradicionais que ela se lembra do tempo em que era estudante. De modo similar, Kang e Wallace (2004) analisaram como crenças epistemológicas e objetivos de ensino estão relacionadas com as práticas de laboratório de professores de ciências. Com base no trabalho de Belenky et al. (1986), as autoras enfatizaram duas dimensões: o aspecto ontológico (certeza/diversidade de verdades); e o aspecto relacional (relação entre conhecedor e conhecido).

Ao investigar a lacuna de gênero nos cursos de Física em Israel, Zohar e Cela (2003) analisaram exames de admissão de aproximadamente 400 escolas secundárias num período de 12 anos e realizaram entrevistas semi-estruturadas com 50 alunos de Física, 25 meninos e 25 meninas. Os resultados mostraram que a participação de meninos e meninas é de 4 para 1 e que o desempenho de meninos e meninas nos exames admissionais são semelhantes. No entanto, as entrevistas revelaram dois fatores que são desfavoráveis para as meninas: a excessiva competição e a falta de um ensino para o entendimento. Com base no trabalho de Belenky et al. (1986), os autores descreveram o anseio das meninas por um entendimento profundo como "uma busca por Conhecimento conectado" (Zohar \& Sela, 2003). Em outro artigo, de cunho mais teórico, Zohar (2006) analisa a relação entre a noção de "aprendizagem para o entendimento" e o "Conhecimento conectado". De acordo com a autora, apesar de virem de perspectivas totalmente distintas e de usarem quadros conceituais bastante diversos, importantes semelhanças podem 
ser traçadas entre o Conhecimento conectado e algumas ideias predominantes da área advindas do ensino e aprendizagem para o entendimento.

Finalmente, Buck et al. (2008) utilizaram as noções de Conhecimento separado e de Conhecimento conectado para analisar os processos cognitivos de meninas adolescentes e de mulheres cientistas que são utilizados para identificar modelos de papéis da ciência. De acordo com as autoras, as meninas adolescentes adotam um modo conectado de pensar uma vez que elas tendem a se identificar apenas com pessoas com quem elas já têm um relacionamento pessoal mais profundo (pais, mães, professores, etc.). Quando perguntadas sobre se cientistas mulheres poderiam servir de modelos para a construção de suas identidades, a resposta tende a ser não. Somente quando elas constroem uma relação pessoal com uma mulher cientista é que elas passam a vê-las não apenas como modelos de cientistas, mas como modelos "para elas" (Buck et al., 2008, p. 704). Já as cientistas mulheres adotam um modo separado de pensar. Elas falam sobre a necessidade de serem modelos perfeitas para atrair mais meninas para a ciência e falham em perceber que a maioria das meninas gostaria de conhecê-las num nível mais pessoal.

Ao revisar os trabalhos que adotam o referencial de Belenky et al. (1986), consideramos que uma apropriação não essencialista e crítica de sua obra pode trazer grandes contribuições para o ensino de ciências no Brasil. Segundo Barton (1998), a segunda onda do feminismo influenciou a educação científica de forma que os estudos passaram a questionar a natureza e práticas da própria ciência e as formas de conhecer a ciência. Esses estudos também defenderam um ensino inclusivo de gênero que buscasse incorporar formas marginalizadas do saber. No Brasil, existem poucos estudos no ensino de ciências que abordam essas questões. Nesse sentido, embora superado em discussões teóricas na sociologia, acreditamos que as implicações da segunda onda do feminismo ainda não se esgotaram, na prática, no contexto da educação científica brasileira.

Uma das críticas das feministas da segunda onda à Ciência Moderna é de que ela se desenvolveu pautada numa estrutura conceitual baseada numa lógica binária como mente/corpo, sujeito/objeto, razão/emoção, objetividade/subjetividade, etc (Sardenberg, 2002). Nessa lógica, os conceitos que são atribuídos à prática científica - mente, sujeito, razão e objetividade - são culturalmente atribuídos, e construídos, como "masculinos". Já os demais conceitos são atribuídos ao "feminino" e passam a ser considerados inferiores (Sardenberg, 2002). Essa lógica binária ainda está muito presente no ensino de ciências no Brasil, onde o ensino tradicional é muito pautado no Conhecimento separado, que é um modo de conhecer baseado nos conceitos "masculinos". Dessa forma, mesmo que a obra de Belenky et al. (1986) situe-se num contexto norte-americano, e da década de 1980, ela aborda questões que podem contribuir para as questões de gênero no ensino de ciências no Brasil. 


\section{Implicações para a Sala de Aula: o Ensino Conectado}

Ao descrever e defender o Conhecimento conectado, as autoras não estão sugerindo que essa posição é melhor do que a do Conhecimento separado. O argumento é de que o Conhecimento conectado é uma "voz diferente", legítima e efetiva, e que merece ser ouvida (Clinchy, 1989). Tendo em vista que essas duas vozes em questão não são mutuamente excludentes (Galotti et al., 1999), é provável que uma seja mais efetiva em um contexto enquanto que a outra seja mais efetiva em outro. Assim, idealmente, seria adequado que todos alunos, meninos e meninas, aprendessem as duas formas de pensar e, eventualmente, conseguissem integrar as duas vozes. Infelizmente, isso não é o que acontece. Nas aulas de ciências é privilegiada a voz do Conhecimento separado. Dessa forma, os meninos podem "falar ciência" (Lemke, 1990) mais facilmente que as meninas e podem nunca aprender a pensar em uma voz conectada. Com vistas a promover uma formação que atenda de modo mais adequado os interesses e necessidades das mulheres, Belenky et al. (1986) propõe uma abordagem instrucional que elas denominam de "ensino conectado".

O ensino conectado é um modelo no qual o(a) professor(a) especialista não exerce poder sobre seus alunos, mas busca ajudá-los nos seus próprios termos. Ele(a) busca examinar as necessidades e capacidades de seus estudantes e compõe uma mensagem que seja cortês com eles(as) (Belenky et al., 1986). Para promover um ensino conectado, é necessário combater o ensino tradicional, que segue o modelo de "educação bancária" no sentido freireano (Freire, 1987). Ao receber os "depósitos" do(a) professor(a), os alunos têm contato apenas com o produto final do seu pensamento. O processo de elaboração do pensamento é escondido de vista uma vez que o(a) professor(a) compõe os seus pensamentos de modo privado. Ao esconder os processos imperfeitos de criação do seu pensamento, o(a) professor(a) dá a impressão de que somente pessoas geniais conseguem pensar daquela forma. Nas aulas de ciências, esse problema é ainda mais acentuado, pois, apesar de as palavras do(a) professor(a) se referirem a modelos, ele(a) os apresentam como se fossem fatos. Essa postura faz parecer que a ciência não é uma criação da mente humana.

Com relação à autoridade dos educadores, $\mathrm{o}(\mathrm{a})$ professor(a) de ciências aparece inicialmente disfarçado como um "deus" e só mais tarde é revelada a sua forma humana, com defeitos e inseguranças. Essa forma humana poderia ser revelada mais cedo se o(a) professor(a) tivesse a prática de pensar em voz alta com os seus estudantes. Seria importante para muitos alunos verem os seus professores de ciências resolverem um problema novo e, eventualmente, falharem em resolvê-lo. Além disso, muitos alunos não gostam de ser tratados como se não tivessem qualquer conhecimento prévio. Para eles, o(a) professor(a) ideal é aquele(a) que os ajuda a expandir o conhecimento que eles já possuem. As autoras se referem a esse tipo de professor(a) com "professor(a) parteiro(a)"' (Belenky et al., 1986, p. 217), pois eles ajudam os estudantes a dar a luz às

8 Compreendemos que a analogia utilizada por Belenky et al. (1986) entre conhecimento, protagonismo, cesariana e parto natural pode não ser a mais adequada nos tempos atuais em função das diversas discussões sobre esses temas na área da Sociologia. No entanto, por se tratar de um conceito central na obra de Belenky et al. (1986), optamos por manter o conceito e analogia feita pelas autoras. 
suas próprias ideias. Já o ensino tradicional seria como uma cesariana, em que a mãe anestesiada se torna uma espectadora passiva do nascimento de seu filho. Assim, ao apresentar os conhecimentos científicos, o(a) professor(a) parteiro(a) prefere mostrar a seus alunos que eles já possuem certas ferramentas para construir um conhecimento poderoso do que ensinar a importante lição de que eles não podem confiar em suas experiências.

Para o ensino conectado, é importante que o(a) professor(a) veja os seus alunos nos seus próprios termos. Em vez de tratar os alunos como se eles fossem uma caixa de ressonância, que ressoa as suas próprias opiniões e pensamentos, o(a) professor(a) parteiro(a) prefere acolher as diversas opiniões que emergem da sala de aula. Por exemplo, em vez de tentar convencer o(a) aluno(a) que detesta ciências de que a sua disciplina é maravilhosa e divertida, o(a) professor(a) parteiro(a) busca entender o ponto de vista do(a) aluno(a), de que ciências pode ser difícil, confusa e entediante. Assim, o(a) professor(a) passa a enfrentar as dificuldades junto com o(a) aluno(a). O ensino conectado busca estabelecer uma relação mais profunda com os estudantes. Em vez de perguntar o que os alunos não entenderam sobre certo conteúdo, o(a) professor(a) parteiro(a) começa perguntando o que esse conteúdo acrescentou em suas vidas. Não é preciso estabelecer um relacionamento pessoal e duradouro com cada estudante, mas é preciso estar inteiramente presente sempre que o(a) aluno(a) recorrer ao professor ou a professora. É importante destacar que o(a) professor(a) parteiro(a) desempenha um papel de autoridade. No entanto, sua autoridade é baseada na colaboração e não na relação de subordinação.

\section{Considerações Finais}

Neste trabalho, apresentamos as maneiras de conhecer das mulheres como possível referencial teórico para os estudos de gênero na educação em ciências. Mostramos como a abordagem de Belenky et al. (1986) têm sido usada em pesquisas da área e traçamos algumas implicações das diferentes perspectivas, em particular do Conhecimento conectado, para o planejamento de intervenções em sala de aula que estejam comprometidos com a equidade de gênero no ensino de ciências. Conforme comentamos na introdução deste manuscrito, as maneiras de conhecer das mulheres estão circunscritas dentro da perspectiva do feminismo da diferença - também conhecido como segunda onda feminista - e, portanto, estão sujeitas às mesmas críticas dirigidas a essa última. Assim, é fácil perceber que, ao denunciar a sistemática exclusão das mulheres dos estudos sobre a psicologia do desenvolvimento (que investigam majoritariamente homens, mas assumem que os resultados são aplicáveis a todos os seres humanos, independentemente do gênero e de outros marcadores socioculturais como raça, etnia e classe social), as autoras acabam substituindo a perspectiva masculina por outra voz, supostamente feminina, que deveria servir de norma para todas as mulheres. Em geral, a segunda onda feminista é criticada por marginalizar as experiências de mulheres que não sejam brancas e pertencentes à classe média (Scantlebury et al., 2010). 
No entanto, não acreditamos que essas críticas se apliquem à abordagem proposta por Belenky et al. (1986). Primeiro porque as autoras contemplaram em suas entrevistas uma diversidade contextual bastante significativa em termos de idade, raça, status socioeconômico e nível de instrução, incluindo moradoras de zonas rurais e urbanas. Segundo porque as cinco posições epistemológicas delineadas pelas autoras (seis se considerarmos que o Conhecimento processual se desdobra em dois tipos: Conhecimento separado e Conhecimento conectado) não devem ser entendidas como categorias fixas e universais - elas próprias reconhecem que essas posições são categorias abstratas que não capturam adequadamente a complexidade do pensamento das mulheres. É verdade que elas não informaram quantas mulheres fazem parte de cada perspectiva epistemológica (Crawford, 1989) e não especificaram de forma mais explicita questões éticas e raciais (Banks-Wallace, 2000). Mesmo assim, a segunda e a terceira onda feminista coexistem atualmente em uma diversidade de pontos de vista, incluindo "o feminismo liberal, o feminismo radical, o feminismo negro, o feminismo pós-colonial, o feminismo pós-estruturalista, o feminismo socialista, o feminismo multiracial, o ecofeminismo e o feminismo crítico", entre outros (Scantlebury et al., 2010, p. 3). Mesmo que o leitor ou leitora não compartilhe das premissas assumidas pelas autoras, é possível perceber as virtudes de sua abordagem se adotarmos a perspectiva do Conhecimento conectado. Em vez de "apontar falhas no argumento", como é característico do Conhecimento separado (e do atual debate sobre questões de gênero em diversos contextos), poderíamos buscar entender o ponto de vista das autoras "nos próprios termos delas". Afinal, não encontramos na literatura trabalhos que explorem as concepções epistemológicas no contexto brasileiro. E no cenário político em que vivemos atualmente, reconhecer diferenças e lutar por equidade de gênero parece ser uma agenda bastante urgente.

\section{Agradecimentos}

Os autores agradecem à Coordenação de Aperfeiçoamento de Pessoal de Nível Superior (Capes) e ao Conselho Nacional de Desenvolvimento Científico e Tecnológico (CNPq) - projeto No 409980/2018-8 - pelo financiamento recebido.

\section{Referências}

Banks-Wallace, J. (2000). Womanist ways of knowing: Theoretical considerations for research with African American women. Advances in Nursing Science, 22(3), 33-45. https://doi.org/10.1097/00012272-200003000-00004

Barton, A. C. (1998). Feminist science education. Teachers College Press.

Belenky, M. F., Clinchy, B. M., Goldberger, N. R., \& Tarule, J. M. (1986). Women's ways of knowing: The development of self, voice, and mind. Basic Book.

Belenky, M. F. (1996). Public homeplaces: Nurturing the development of people, families, and communities. In N. R. Goldberger, J. M. Tarule, B. Clinchy McVicker, \& M. F. Belenky (Eds.), Knowledge, difference, and power: Essays inspired by "Women's Ways of Knowing." (pp. 393-430). Basic Books. 
Brickhouse, N. W. (2001). Embodying science: a feminist perspective on learning. Journal of Research in Science Teaching, 38(3), 282-295. https://doi.org/10.1002/10982736(200103)38:3<282::AID-TEA1006>3.0.CO;2-0

Brotman, J. S., \& Moore, F. M. (2008). Girls and science: A review of four themes in the science education literature. Journal of Research in Science Teaching, 45(9), 971-1002. https://doi.org/10.1002/tea.20241

Buck, G.A., Clark, V.L., Leslie-Pelecky, D.L., Lu, Y., \& Cerda-Lizarraga, P.R. (2008). Examining the Cognitive Processes Used by Adolescent Girls and Women Scientists in Identifying Science Role Models: A Feminist Approach. Science Education, 92(4), 688707. https://doi.org/10.1002/sce.20257

Clinchy, B. M. (1989). The Development of Thoughtfulness in College Women: Integrating Reason and Care. American Behavioral Scientist, 32(6), 647-657. https://doi. org/10.1177/0002764289032006005

Clinchy, B. M. (1990). Issues of Gender in Teaching and Learning. Journal of excellence in college teaching, 1, 52-67.

Clinchy, B. M. (2002). Revisiting Women's Way of Knowing. In B. K. Hofer \& P. R. Pintrich (Eds.), Personal epistemology: The psychology of beliefs about knowledge and knowing (pp. 63-87). Lawrence Erlbaum Associates Publishers.

Comitê Nacional de Educação em Direitos Humanos (2007). Plano Nacional de Educação em Direitos Humanos. Secretaria Especial dos Direitos Humanos. Ministério da Educação, Ministério da Justiça, Unesco, 2007.

Constituição da República Federativa do Brasil (1988). Constituição da República Federativa do Brasil. Senado Federal.

Costa, C. D. L. (2002). O sujeito no feminismo: Revisitando os debates. Cadernos Pagu, (19), 59-90. https://doi.org/10.1590/S0104-83332002000200004

Crawford, M. (1989). Agreeing to differ: Feminist epistemologies and women's ways of knowing. In M. Crawford \& M. Gentry (Eds.), Gender and thought: Psychological perspectives (pp. 128-145). Springer.

Cruz, M. H. S. (2014). A Crítica Feminista à Ciência e Contribuição à Pesquisa nas Ciências Humanas. Revista Tempos e Espaços em Educação, 7(12), 15-27, 2014. https:// doi.org/10.20952/revtee.v0i0.2949

Eick, C. J., \& Reed, C. J. (2001). What Makes an Inquiry-Oriented Science Teacher? The Influence of Learning Histories on Student Teacher Role Identity and Practice. Science Education, 86(3), 401-416. https://doi.org/10.1002/sce.10020

Freire, P. (1987). Pedagogia do Oprimido. $17^{\mathrm{a}}$ ed. Paz e Terra.

Galotti, K. M., Lavin, B., Mansfield, A., Ainsworth, K., \& Clinchy B. (1999). A new way of assessing ways of knowing: The attitudes toward thinking and learning survey (ATTLS). Sex Roles, 40, 745-766. https://doi.org/10.1023/A:1018860702422 
Gilligan, C. (1983). In a Different Voice: Psychological Theory and Women's Development. Harvard University Press.

Haraway, D. (1988). Situated Knowledges: The Science Question in Feminism and the Privilege of Partial Perspective. Feminist Studies, 14(3), 575-599. https://doi. org $/ 10.2307 / 3178066$

Harding, S. (1986). The Science Question in Feminism. Cornell University Press.

Harding, S. (1992). Rethinking standpoint epistemology: what is "strong objectivity?" The Centennial Review, 36(3), 437-470.

Heerdt, B., Santos, A., Bruel, A., Ferreira, F., Anjos, M., Swiech, M., \& Banckes, T. (2018). Gênero no ensino de Ciências publicações em periódicos no Brasil: O estado do conhecimento. Revista Brasileira de Educação em Ciências e Educação Matemática, 2(2), 217-241. http://dx.doi.org/10.33238/ReBECEM.2018.v.2.n.2.20020

Howes, E. V. (2002). Connecting girls and science. Constructivism, feminism, and education reform. Teachers College Press.

International Labour Organization (ILO) (2000). ABC of Women Worker's Rights and Gender Equality. ILO.

Ireland, D. T., Freeman, K. E., Winston-Proctor, C. E., DeLaine, K. D., McDonald Lowe, S., \& Woodson, K. M. (2018). (Un)hidden figures: A synthesis of research examining the intersectional experiences of black women and girls in STEM education. Review of Research in Education, 42(1), 226-254. https://doi.org/10.3102/0091732X18759072

Jones, M. G., Howe, A. N. N., \& Rua, M. J. (2000). Gender Differences in Students' Experiences, Interests, and Attitudes toward Science and Scientists. Science Education, 84(2), 180-192. https://doi.org/10.1002/(SICI)1098-237X(200003)84:2<180::AIDSCE3>3.0.CO;2-X

Kang, N., \& Wallace, C. S. (2004). Secondary Science Teachers' Use of Laboratory Activities: Linking Epistemological Beliefs, Goals, and Practices. Science Education, 89(1), 140-165. https://doi.org/10.1002/sce.20013

Keller, E. F. (1982). Feminism and Science. Sings: Journal of Women in Culture and Society, 7(3), 589-602.

Khine, M. S., \& Hayes, B. (2010). Investigating women's ways of knowing: An exploratory study in the UAE. Issues in Educational Research, 20(2),105-117.

Kohlberg, L. (1981). The philosophy of moral development. Harper \& Row.

Lei n. 11.340, de 7 de agosto de 2006 (2006). Coíbe a violência doméstica e familiar contra a mulher. Presidência da República. Brasília, DF.

Lei n. 13.005, de 25 de junho de 2014 (2014). Aprova o Plano Nacional de Educação PNE e dá outras providências. Presidência da República. Brasília, DF. 
Lemke, J. L. (1990). Talking Science: Language, Learning and Values. Ablex Publishing Corporation.

MEC (2001). Diretrizes Nacionais para a Educação Especial na Educação Básica. Parecer CNE/CEB no 17 200, de 17 de agosto de 2001. Brasília: Diário Oficial da União.

MEC (2004). Diretrizes Curriculares Nacionais para a Educação das Relações ÉtnicoRaciais e para o Ensino de História e Cultura Afro-Brasileira e Africana. Parecer CNE/CP no 3 de 2004. Brasília: Diário oficial da União.

MEC(2010). Diretrizes Operacionais para a Educação de Jovens e Adultos. Conselho Nacional de Educação. Parecer CNE/CEB n 3, de 15 de junho de 2010. Brasília: Diário Oficial da União.

MEC (2012a). Diretrizes Nacionais para a Educação em Direitos Humanos. Conselho Nacional de Educação. Parecer CNE/CP n. ${ }^{\circ}$ 8, de 6 de março de 2012. Brasília: Diário Oficial da União.

MEC (2012b). Diretrizes Curriculares Nacionais para a Educação Ambiental. Resolução CNE/CP n², de 15 de junho de 2012. Brasília: Diário Oficial da União.

MEC (2012c). Diretrizes Curriculares Nacionais para a Educação Escolar Indígena na Educação Básica. Resolução CNE/CEB no 5, de 22 de junho de 2012. Brasília: Diário Oficial da União.

MEC (2012d). Diretrizes Curriculares Nacionais para a Educação Escolar Quilombola. Resolução CNE/CEB nº 8, de 20 de novembro de 2012. Brasília: Diário Oficial da União.

Perry, W. G. (1970). Forms of intellectual and ethical development in the college years. Holt, Rinehart \& Winston.

Proença, A. O., Baldaquim, M. J., Batista, I. L., \& Broietti, F. C. (2019). Tendências das Pesquisas de Gênero na Formação Docente em Ciências no Brasil. Química Nova na Escola, 41(1), 98-107. https://doi.org/10.21577/0104-8899.20160145

Sardenberg, C. M. B.(2002) Da crítica feminista à Ciência a uma Ciência Feminista?. In A. A. Costa, \& C. M. B. Sardenberg (Org.) Feminismo, Ciência e Tecnologia (pp. 89-120). REDOR/NEIM-FFCH/UFBA, vol.8 Coleção Bahianas, 2002.

Scantlebury, K., Martin, S., \& Butler Kahle, J. (2010). Women in science Education: Introduction and historical overview. In K. Scantlebury, J. Butler Kahle \& S. N. Martin (Eds.), Re-visioning Science Education from Feminist Perspectives: Challenges, Choices, and Careers (pp. 3-7). Sense Publishers.

Sinnes, A. T., \& Løken, M. (2014). Gendered education in a gendered world: Looking beyond cosmetic solutions to the gender gap in science. Cultural Studies of Science Education, 9(2), 343-364. https://doi.org/10.1007/s11422-012-9433-Z 
Zohar, A., \& Sela, D. (2003). Her physics, his physics: Gender issues in Israeli advanced placement physics classes. International Journal of Science and Education, 25(2), 245268. https://doi.org/10.1080/09500690210126766

Zohar, A. (2006). Connected Knowledge in Science and Mathematics Education. International Journal of Science Education, 28(13), 1579-1599. https://oi. org/10.1080/09500690500439199

\section{Laís Gedoz}

(1) https://orcid.org/0000-0003-3008-7912 Universidade Federal do Rio Grande do Sul Instituto de Física, Programa de Pós-Graduação em Ensino de Física Porto Alegre, Rio Grande do Sul, Brasil lais.gedoz@ufrgs.br

Alexsandro Pereira de Pereira

(1) https://orcid.org/0000-0001-8689-3054 Universidade Federal do Rio Grande do Sul Instituto de Física Departamento de Física Porto Alegre, Rio Grande do Sul, Brasil alexsandro.pereira@ufrgs.br

Daniela Borges Pavani

${ }^{\circ}$ https://orcid.org/0000-0001-8543-9765 Universidade Federal do Rio Grande do Sul Instituto de Física, Departamento de Astronomia Porto Alegre, Rio Grande do Sul, Brasil dpavani@if.ufrgs.br

Submetido em 18 de março de 2020 Aceito em 01 de julho de 2020 Publicado em 17 de agosto de 2020 